\title{
Colouterine Fistula
}

\author{
LHBANU $^{\mathrm{a}}$, A SIDDIQUA ${ }^{\mathrm{b}}$, S SIDDIQUE $^{\mathrm{c}}$
}

\begin{abstract}
Summary:
Colouterine fistula is a extremely rare condition.It may be congenital,iatrogenic or secondary to malignancy.Here we report a congenital type of colouterine fistula with successful primary repair without hysterectomy in a nulliparous
\end{abstract}

\section{Introduction:}

Colouterine fistula is an extremely rare condition because the uterus is a thick, muscular organ. It can be congenital or may be caused by foreign body, during surgery, following trauma or accidental or secondary to malignancy, diverticulitis \& endometriosis. This condition can be deleterious for an infertile female because of introduction of infection via the colon. Treatment of colouterine fistula in parous women is hysterectomy followed by repair of rent in the colon. We present the case of a colouterine fistula in which repair of the uterus was done as primary procedure and colostomy done for sigmoid fistula. The uterus was conserved because the patient was a nulliparous woman.

\section{Case Report:}

A 18 years old married girl resident of Kamarpara, Shadullapur, Gaibandha, educated upto class ten, admitted in surgery ward of Prime Medical College \& Hospital, Rangpur on 14.7.2013, presented as 5 months pregnancy with bouts of per rectal bleeding for 3 days $\&$ lower abdominal pain for 4 days. On admission, patient was moderately anaemic, pulse, blood pressure normal, abdomen tense and tender, fundal height of uterus was

a. Dr. Laila Husna Banu, Professor \& Head of the Department of Obs. \& Gynae, Prime Medical College \& Hospital, Rangpur.

b. Dr. Afroja Siddiqua, Assistant Professor of Obs \& Gynae, Northern (Pvt.) Medical College \& Hospital, Rangpur.

c. Dr. Sohana Siddique, Assistant Professor of Obs \& Gynae, Jahurul Islam Medical College \& Hospital, Bhagolpur, Bajitpur, Kishoreganj.

Address of Correspondence: Dr. Afroja Siddiqua, Assistant Professor of Obs \& Gynae, Northern (Pvt.) Medical College \& Hospital, Rangpur, Mobile: 01712-552407

Received: 23 March 2014

Accepted: 16 Sept. 2016
woman.Usually treatment of a parous women is hysterectomy followed by repair of rent in the colon.

Key words: Colouterine fistula, cause, diagnosis, treatment. (J Bangladesh Coll Phys Surg 2017; 35: 31-33)

24 weeks size. USG findings was 22 weeks pregnancy, placenta posterior away from the os with active fetal movement \& cardiac activity, no sign of intestinal obstruction. Conservative treatment and boold transfusion started in the surgery ward as there was severe per rectal bleeding. One day after admission abortion process was started $\&$ on the next day early morning on 16.7.2013 she complained that something coming out per rectum. The attending doctors of surgery unit found that the placenta was outside through rectum $\&$ the umbilical cord was hanging from anus (fig-1). The patient was then transferred to gynae ward \& on per vaginal examination a very premature infected dead foetus with foul smelling was found protruding through cervix with breech presentation (fig-2). Oxytocin drip was started for spontaneous expulsion of the foetus but still waiting up to mid noon there was no progress. So planned for examination under anesthesia and breech extraction. Under spinal anesthesia just a pull for extraction of the foetus the head was separated from the neck \& retained inside the uterus. Then decision was taken for laparotomy \& hysterotomy to remove the retained aftercoming head of breech. Abdomen was opened by right lower paramedian incision. The abdominal cavity was contaminated with fecal matter. The uterus was enlarge about 24 weeks size $\&$ part of the sigmoid colon was found adherent to anterior upper segment of uterus. So, the case was diagnosed as colouterine fistula, possibly congenital, which is extremely rare condition. The attachment was very dense \& clean cut well defined, no omental or any other surrounding adhesion was found(fig-3). Surgery team dissected and separated the sigmoid colon from the uterus. A big hole in the anterior uterine wall near fundus admits two finger through which the retained head was searched but not found. Ultimately the head was found 
in rectum which was driven down through the large fistula to the capacious colon to rectum \& was brought out per rectum by an assistant. The big hole of the uterus was then closed with vicryl 1 in two layers. Colostomy was done at the level of sigmoid fistula by Hartman's procedure. Peritoneal toileting was done \& a drain tube was placed in pelvic cavity. Abdomen was closed in layers. Patient was put on broad spectrum antibiotics \& nothing per oral for seven days. Total six units blood was transfused. The post-operative period was uneventful except the abdominal wound got infected \& secondary suture was given on 3.8.2013. The patient was discharged after ten days \& adviced to come for follow up.

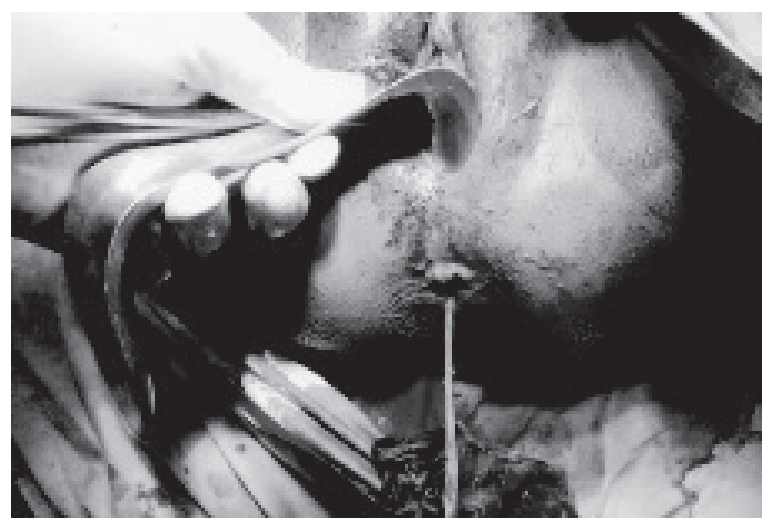

Fig.-1: The umbilical cord was hanging per rectum \& anus from where placenta was delivered first.

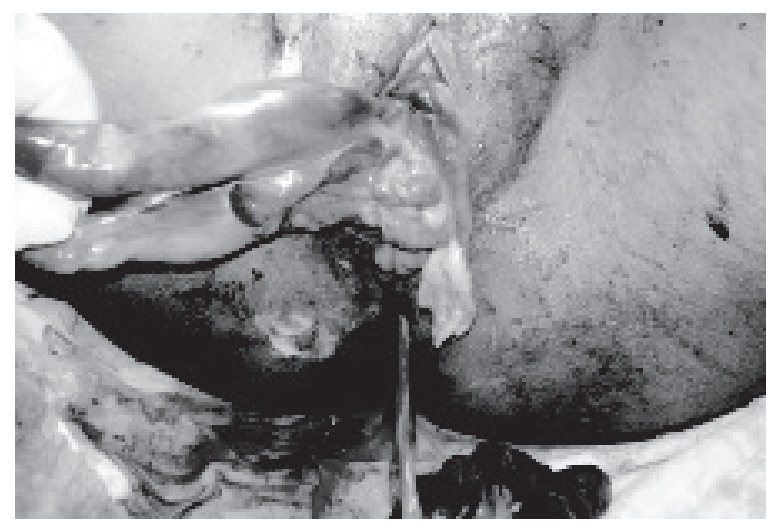

Fig.-2: Aborted foetus delivered vaginally with breech presentation \& the umbilical cord was hanging from anus.

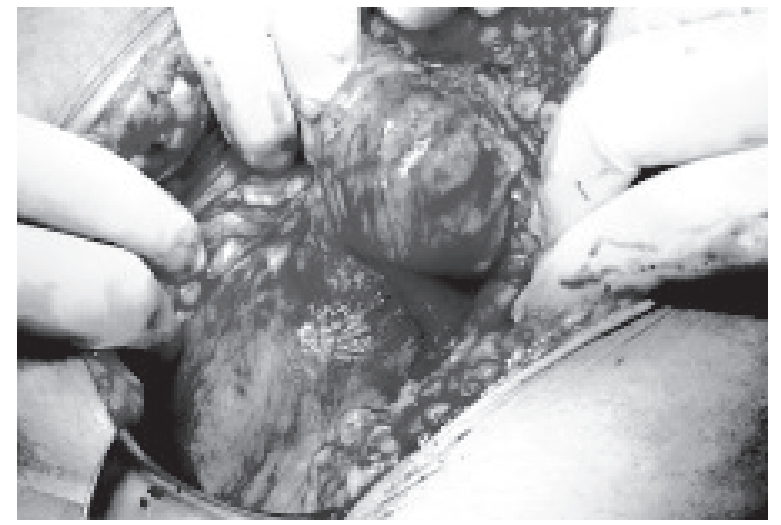

Fig.-3: Laparotomy shows fistula in between the uterus \& sigmoid colon.

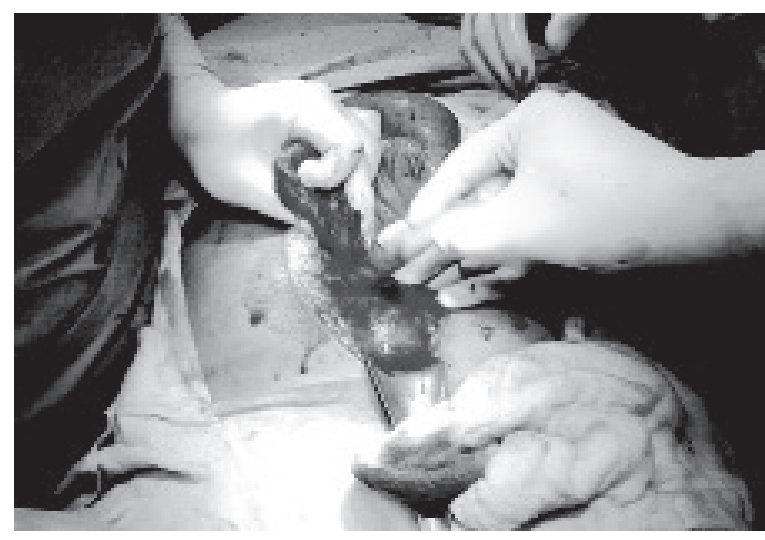

Fig.-4: Separation \& dissection of fistula was done.

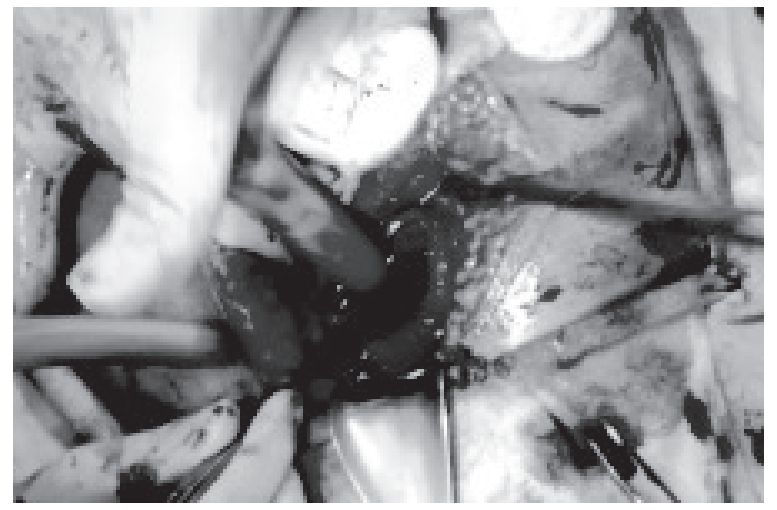

Fig.-5: This figure shows fistula at the uterine site after dissection from sigmoid colon.

\section{Discussion:}

Since long vaginal deliveries with obstetric \& gynaecological interventions have been associated with vesicovaginal $\&$ rectovaginal fistulae ${ }^{1}$. Vesicouterine fistulae are relatively rare but world literature documents 
only few case of colouterine fistula ${ }^{2}$. Usually these cases of colouterine fistulae were diagnosed by computerized tomography ${ }^{3}$ or sonohysterography ${ }^{4}$. Just a conventional hysterosalpingography can also lead to the diagnosis ${ }^{5}$. Colouterine fistulae documented till now were secondary to malignancy ${ }^{6}$, diverticulitis ${ }^{6}$ \& endometriosis. All these cases were treated by hysterectomy \& resection of sigmoid colon ${ }^{7}$ or colostomy with subsequent repair ${ }^{8}$. We report this case of colouterine fistula with successful primary repair of uterus without hysterectomy.

Initial evaluation comprises a detailed history. Important information includes associated symptoms such as pain, fever or changes in bowel or bladder function. Although clinical manifestations of a colouterine fistula vary according to causative pathology, typical symptoms include malodorous fecal or purulent vaginal discharge for days or months because the colonic lumen \& the uterus are linked via a fistula tract ${ }^{9,10,11}$. In our case we suspect the fistula is congenital type, though there was no history of per rectal bleeding during menstruation nor any symptoms of malodourous fecal or purulent vaginal discharge. It is probably due to, the non-pregnant uterus is small and the fistular attachment with colon is partially closed and non-communicating. But when the patient became pregnant the uterus enlarged and the muscle wall comparatively thinner. The placenta implanted at or near the site of fistula. Subsequently the fistula opened up and due to separation of placenta there was severe per rectal bleeding and lower abdominal pain, the symptoms which appeared first. Later on the whole placenta separated and through the fistula it passed to the sigmoid colon, rectum, anal canal and ultimately come out through anus (Fig:1). So, the colouterine fistula was diagnosed as a congenital type and primary repair of uterus was done successfully. From patient detailed history, she got married just six month back and it was her first conception. There was no history of MR or induced abortion or any injury or trauma which may favour the diagnosis of acquired variety of fistula.

In conclusion a uterocloic fistula is a very very rare condition. Computed tomography (CT) is routinely performed for diagnosis is patients with a suspected colouterine fistula. However, confirming the diagnosis by using computed tomography (CT) might be difficult. Therefore other less-invasive modalities such as fistulography may be necessary $\&$ the utility of recently introduced modalities remains to be verified.

\section{References:}

1. Sotelo R, Mariano MB, Garcia-Segui A, Dubois R, Spaliviero M, Keklikian W, Novoa J, Yaime H, Finelli A. Laparoscopic repair of vesicovaginal fistula. J Urol 2005;173(5):1615-8.

2. Beattie GC, Nelson M, McMillen IM, McMurray AH. Colouterine fistula mimicking pyometrium-diagnosis established with multi-detector computed tomography. Ulster Med J 2005;74(1):51-3.

3. Andrew G, Harold VP, Richard AC. Colouterine fistula: computed tomography and vaginography findings, Can Assoc Radiol J 1996;47:186-8.

4. Takada T, Nakagawa S, Hashimoto K, Sone K. Preoperative diagnosis of colouterine fistula secondary to diverticulitis by sonohysterography with contrast medium. Ultrasound in Obstetrics and Gynecology 2004;24(6):682-3.

5. Dr.Aliya Islam, Associated professor Gynaecology, Military Hospital, Rawalpindi, Pakistan, present a case report on colouterine fistule with a foreign body. J Minim Invasive Gynecol. 2008 Sep-Oct;15(5):652-4. doi: 10.1016/j.jmig.2008.06.014.

6. Elliot LC, Richard PC, Andrew LW. Colouterine fistula secondary to diverticulitis. Diseases of the Colon \& Rectum 1985;28(5):358-60.

7. Hoekstra AV, Doan T, Kosinski A, Dini M. Colouterine fistulas in elderly women: a report of 2 cases. J Reprod Med 2005;50(10):796-800.

8. Al-Azzam M, Cassidy L, Thomas M. Colouterine fistula as a complication of colonic diverticulitis: a conservative approach. Gynaecol Endoscop 2002;11(4):215-6.

9. Chaikof EL, Cambria RP, Warshaw AL. Colouterine fistula secondary to diverticulitis. Dis Colon Rectum 1985;28:358-60.

10. Sentilhes L, Foulatier O, Verspyck E, Roman H, Scotte M, Mar-peau L. Colouterine fistula complicating diverticulitis: a case re-port and review of the literature. Eur J Obstet Gynecol Reprod Biol 2003;110:107-10.

11. Vilallonga R, Baena JA, Fort JM, Gonzalez O, Gemar E, Armen-gol Carrasco M. Colouterine fistula complicating diverticulitis in elderly women. Int J Colorectal Dis 2009;24:599-600. 